\title{
Bioethics Here and in Poor Countries: A Comment
}

\author{
KLAUS M. LEISINGER
}

There has been a tremendous increase in interest in bioethics, which has come in direct response to the substantial advances in biomedical research and medical technology over the past 30 years. The more sophisticated medical science and technology becomes, the more sophisticated are questions that are raised: Who has the right to decide whether a medical treatment should be initiated, continued, or stopped? How much information are healthcare professionals required to give to patients? When should a patient's right to confidentiality be violated? When, if ever, is active or passive euthanasia or abortion justified, and who has the right to decide on these issues?

In books like Contemporary Issues in Bioethics, ${ }^{1}$ intellectually appealing questions about the beginning and end of life, euthanasia, prolongation of life, abortion, patients' rights, and professional responsibility are in the center of the debate. Advances in technology and scarce financial resources also require ethical reflections on issues in biomedical research and the allocation of available health resources. These matters, involving individual moral judgement and consequent actions, also raise questions of policy, law, professional ethics, and even economics.

I do not intend to diminish the importance of this whole cluster of issues that are discussed in affluent societies like the United States. But I do think that matters of life and health are not limited to medical and scientific issues. The widening disparities between the rich countries and the poor Third World countries, for example, and the increase in people living in absolute poverty represent an ever increasing danger for peace, justice, and the protection of our natural environment. Improper waste disposal jeopardizes the health of human beings all over the world, threatens the globe, and impairs the quality of life of future generations. Although bioethics overlaps with these areas of concern, it is usually treated in a much narrower sense and hence is distinguished from environmental ethics or development ethics.

\section{Healthcare Policy as a Branch of Bioethics}

Healthcare policy all over the world has its own bioethical problems. In rich nations, vast amounts of money are spent on healthcare, but it is not clear how much money should be spent and by whom, how a system of healthcare should be organized, or how the benefits of such a system should be distributed. As biomedical research and medical technologies have advanced in the rich part of the world, scarcity, e.g., with regard to expensive intensive care unit equipment, sophisticated medicine, specialized practitioners, artificial organs, donors for or- 
gan transplantations, and so on, seems to have increased rather than diminished. Thus, questions of allocation and fair distribution of those resources to satisfy human needs and desires are raised. However, compared to the current issues of healthcare in poor countries, we are rather privileged with these kind of problems.

While we have started to tackle some of our more complex health problems with genetic engineering, hundreds of millions of people in developing countries suffer from malaria, filariasis, schistosomiasis, trypanosomiasis, or leprosy. None of these preventable and/or curable diseases are controlled to a satisfactory degree - for some of them the situation is deteriorating. One and a half billion people in the developing countries are, for cultural, financial, or merely geographical reasons, deprived of any primary healthcare. Thus, people who are too poor to afford private healthcare, who live too far away from even the simplest rural health posts, or who are not properly informed about the shortcomings of traditional medicine die from relatively simple illnesses such as diarrhea.

\section{Mass Poverty: A Bioethical Challenge}

In 1992, after three decades of economic development unprecedented in human history and a likewise explosion of knowledge and technical capabilities, over one billion people live in absolute poverty, "a condition of life so degraded by disease, illiteracy, malnutrition, and squalor as to deny its victims basic human necessities." 2 The number of illiterates - a proxy for the chances of future generations to escape poverty - has risen to 900 million. ${ }^{3}$ All over the world, poverty, rather than any single pathogen, causes death; poverty, rather than any microbe, parasite, or worm, is the key vector for disease. In 1989 in the United States, the risk of dying within the first year of life was 2.3 times greater for black than for white infants, and for all of the leading causes of death, the risk was higher for black than for white infants. ${ }^{4}$

In the developing world, about 280,000 children per week die before they reach the age of 5 because of frequent infection and prolonged undernutrition; that is about 40,000 child deaths each day, and over 400 (one full jumbo jet) while you are reading this discourse. ${ }^{5}$ Each year, nearly three million children die from immunizable diseases. Some 180 million children, one in three in the developing countries, suffer from serious malnutrition. Each year, about half a million women die from causes related to pregnancy and childbirth. ${ }^{6}$

Health and socioeconomic development are interdependent. Significant and lasting improvements in the state of health are one of the most important, if not the most important, preconditions for economic and social development on a broad basis. Significant and lasting improvements in the state of health, particularly of the poorer strata, necessitate improvements in their standard of living and hence sustained economic development.

Therefore, curative and preventive health services can only have a limited and temporary impact on the state of health of the poor majority as long as there is an environment of malnutrition, germ- and parasite-infested water, lack of sanitary facilities, inadequate housing, and widespread ignorance. With absolute poverty prevailing or even increasing, no substantial improvements in the state of health of the poorest can be achieved. However, can we afford to lean back until economic development takes its course and solves all poverty-related problems? 
Can the poor masses be expected to wait until the benefits of economic development "trickle down" to them, if they do so at all?

Better health and lower mortality rates are highest ranking priorities in human hopes and aspirations. Appropriate healthcare could contribute to better chances of survival and a higher quality of life for hundreds of millions of human beings in poor countries - today. Simple programs implemented by UNICEF have demonstrated that it is possible to prevent most child deaths and child malnutrition by means that any developing nation can afford.

Each and every life has its own unmeasurable value, its own unique importance and moral justification and therefore ought to be saved, supported, and protected. We, however, run the danger of focusing on issues that are relevant to a minority in affluent nations only while ignoring human tragedies of unprecedented dimension in the lower strata of today's poor countries. We tend to deal with ever fewer issues in an ever deeper complexity, like minute objects investigated and dissected under the microscope, and we thus lose sight of the entirety and of the most striking problems. Bioethics, as I perceive it, is a holistic discipline and should therefore also have a deeper appreciation of the issues that concern sustainable development policy in poor countries.

\section{Basic Needs Orientation}

Development must be woven around people, not people around development. ${ }^{7}$ The most essential bioethical criterion for an appropriate development policy is a human development path that strives to satisfy the most basic human needs for all members and strata of the society. Hence, the provision of adequate food, primary education, safe drinking water, appropriate sanitation, adequate housing, and primary healthcare must become the development policy priorities. Reaching this objective enlarges the range of people's choices to make development more democratic and participatory.

\section{Restructuring National Budgets According to Human Development Criteria}

To finance the public spending necessary to create the adequate income-earning opportunities and/or to pay for subsidized essential goods and services in poor countries, military expenditure must be frozen, public enterprises reformed, prestige projects dropped, capital flight halted, and corruption combatted. The United Nations Development Program (UNDP) estimated that such a restructuring of national budgets could release nearly $\$ 50$ billion each year. ${ }^{8}$ Another $\$ 55$ billion would become available to the Third World if the developed countries would give up their protectionism against the developing nations. ${ }^{9}$ These two money sources plus today's international funds for development cooperation of approximately $\$ 50$ billion per year would not only allow a development policy in line with bioethics but would also contribute towards a global sustainable development by helping to avoid poverty-related environmentally destructive behavior.

\section{Conclusion}

Because bioethics is not yet an established discipline, it still has the opportunity to widen its scope. However, bioethics must definitely be interdisciplinary to avoid 
the rigidity and one-sidedness of single disciplines. Given the impact of underdevelopment and poverty on an interdependent world, bioethics should be regarded as an academic discipline that deals with those problems as well. Where millions of children die due to the lack of basic healthcare or where millions of orphans are denied the right for parental care and love, the microscopic philosophical debates on reproductive issues such as artificial insemination, in vitro fertilization, and surrogate motherhood seem-in a global context-rather out of proportion.

Besides the ethics of nature, the ethics of life, and the ethics of solidarity, we must consider the time factor as an ethical value as well, because

\begin{abstract}
Every minute lost, every decision delayed, means more deaths from starvation and malnutrition, and means the evolution to irreversibility of phenomena in the environment. No one will ever know for sure the human and financial cost of time ... ${ }^{10}$
\end{abstract}

\title{
Notes
}

1. Beauchamp TL, Walters LR. Contemporary Issues in Bioethics. 3rd ed. Belmont, California: Wadsworth, 1989. See also Young EWD. Alpha \& Omega-Ethics at the Frontier of Life and Death. Menlo Park, California: Addison-Wesley, 1989.

2. As defined by McNamara RS. Address to the Board of Governors. Nairobi, Kenya, 24 September, 1973:6ff.

3. UNESCO. World Educational Report 1991. Paris: UNESCO, 1991:22.

4. Morbidity and Mortality Weekly Report 1992;41(5, Feb. 7):83.

5. UNICEF. The State of the World's Children 1988. New York: UNICEF, 1988:1.

6. Statistical data are from UNDP. Human Development Report 1991. New York: Oxford University Press, 1991:2.

7. See note 6. UNDP. 1991.

8. See note 6. UNDP. 1991:5.

9. World Bank. World Development Report 1991. Washington, D.C.: World Bank, 1991:11.

10. See King A, Schneider B. The First Global Revolution. A Report by the Council of the The Club of Rome. London/New York: Simon and Schuster, 1991. 